\title{
An Optimized Near Perfect Reconstruction Transmultiplexer
}

\author{
Piyush Jain \\ Assistant Professor, Dept. of ECE, SGSITS Indore \\ 21/368-Soni Colony, Guna (M.P.) \\ India 473001
}

\author{
Jitendra Jain \\ Assistant Professor, Dept. of ECE, BIST Bhopal \\ 128-Madhav Nagar Jhansi Road, Gwalior (M.P.) \\ India 474002
}

\begin{abstract}
The design of an optimized near-perfect reconstruction (NPR) type trans-multiplexer has been proposed. Cosine modulation has been used to design the synthesis and analysis sections of the trans-multiplexer. The design of transmultiplexer was reduced to design of single low-pass prototype FIR filter which is designed using variable window function (Kaiser, Cosh and Dolph- Chebyshev). An unconstrained, non-linear, iterative optimization technique Levenberg-Marquardt (LM) has been applied for optimization of filter coefficients such that the prototype filter have minimum value of error in its pass band, transition band and stop band. This results in minimum value of interference parameter like inter-channel interference (ICI) and inter-symbol interference (ISI) that occurs due to interference of filters in their stop-band and non-ideal nature of filters in their pass-band respectively. When compared to the optimized prototype filter designed without using any window function, the proposed method gives better performance in terms of reduction in errors in pass band, transition band and stop band and interference parameters (ICI and ISI) for same filter specification.
\end{abstract}

Keywords- Kaiser, Cosh, Dolph-Chebyshev window, Filter- banks, Cosine Modulation, ICI, ISI, LM Optimization.

\section{INTRODUCTION}

The rapid growth of multicarrier communication system requires a multiplexing system, which is able to transmit several signals simultaneously over the same communication channel. For efficient transmission and perfect recovery of signals, we need to study a kind of a multi-rate sub-system known as a Transmultiplexer. Originally, a Transmultiplexer is known as a TDM-FDM-TDM converter[1], but in this context it is viewed as merely a signal reconstruction problem. Transmultiplexers can be realized as a multi-input, multi-output system that uses sampling rate alteration and filtering to combine $\mathrm{M}$ signals for transmission across a channel and then recover the $\mathrm{M}$ input signals.

It consists of a synthesis block at the transmitter end and precedes the analysis block at the receiver end. At the transmitter end, M-input signals are first interpolated by the factor of $\mathrm{M}$ and synthesized into one composite signal using synthesis filter bank $\mathrm{Fk}(\mathrm{z})$ for $\mathrm{k}=0,1, \ldots \mathrm{M}-1$. Conversely, at the receiver end, the composite signal is split out into $M$ output signals with the help of the analysis filter bank Hk(z) and then decimated by a factor of $\mathrm{M}$. The motive for configuring transmultiplexers is to multiplex $\mathrm{M}$ discrete signals at a certain sampling rate into acomposite signal at $\mathrm{M}$ times the sampling rate (at the transmitter) and then, achieve perfect reconstruction of the inputs (at the receiver). Bandwidth efficiency is achieved by using the full channel bandwidth thereby leaving no gaps in the frequency bands allocated to the input signals. But no guard band between signals can cause overlapping of adjacent signals resulting in interference in same or between different sub-channels. The interference parameters like Interchannel interference (ICI) and Intersymbol interference (ISI) are the main performance parameters of a transmultiplexer system. These interferences can be minimized by proper selection of synthesis and analysis filters.

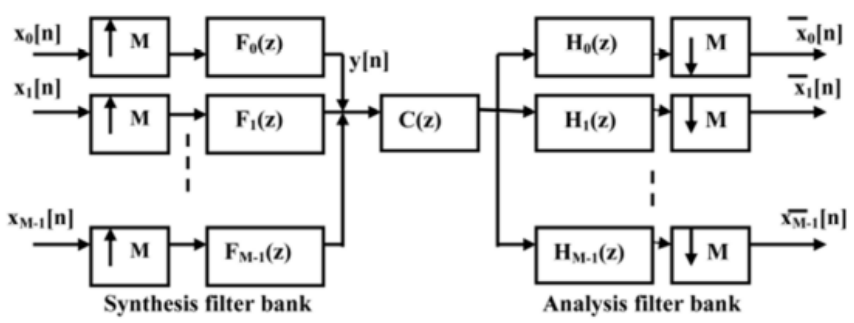

Fig. 1: Block diagram of a M-channel Transmultiplexer

\section{NEED OF TRANSMULTIPLEXERS}

In traditional FDM-TDM conversion, filters used for reconstruction were analog. Due to limitation of analog filter, non-DFT transmultiplexer suffered from crosstalk in between the adjacent channels. The researchers worked on this issue and utilized the multi-rate signal processing theory and developed DFT-based transmultiplexers. The DFT was implemented by FFT. In multicarrier communication, orthogonal frequency division multiplexing (OFDM) and discrete multi-tone transmission (DMT) are the widely used technologies.Both the technologies employ the inverse discrete fourier transform (IDFT) and discrete fourier transform (DFT) for the modulation and demodulation of the signals. Due to multipath fading over wireless communication, the consecutive OFDM symbols overlap at the receiver and gives rise to ISI [2]. In order to minimize the ISI, the OFDM system makes use of the guard band, which results in loss of spectral efficiency[3]. In addition, since the DFT-based modulation filters have side lobes of the order of $-13 \mathrm{~dB}$, the significant spectral overlapbetween the subcarriers causes ICI.The issues discussed above motivate researchers to develop an efficient and guard band less multicarrier communication technology. This has led to existence of filter bank-based multicarrier transmission systems (FB-MCTs), such as the overlapped DMT, filtered multi-tone transmission (FMT) and discrete wavelet multitone transmission (DWMT). These FB-MCTs systems use filters of greater length than the rectangular filters of DMT 
systems and typically yield results with improvement in sidelobes attenuation, lower levels of ICI and ISI and greater robustness to narrow-band interference [4]. C.W.et.al. [5] have suggested cosine modulated filter bank (CMFB) approach in the design of synthesis and analysis section of the TMUX. In these systems, all thefilters are designed in an efficient manner by modulation of a single prototype filter. In the real communication world, where the transmission channel itself introduces considerable distortion, it is better to go for NPR side. In NPR systems, the constraints and complexity of perfect reconstruction (PR) are relaxed by allowing a small amount of interferences. The NPR systemis beneficial since it provides better stop-band performance with less complexity

\section{Analysis OF M-Channel MaXimally DECIMATED TRANSMULTIPLEXER}

Referring to Fig.1, the relation between M-input signals and output of $l^{\text {th }}$ sub-channel in $\mathrm{z}$-domain can be expressed[6]

$$
\begin{aligned}
& \overline{\mathbf{X}}_{\mathrm{l}}(\mathrm{z}) \\
& =\sum_{\mathrm{k}=0}^{\mathrm{M}-1}\left[\frac{1}{\mathrm{M}} \sum_{\mathrm{m}=0}^{\mathrm{M}-1} \mathrm{H}_{\mathrm{l}}\left(\mathrm{z}^{\frac{1}{\mathrm{M}}} \mathrm{W}^{\mathrm{m}}\right) \mathrm{C}\left(\mathrm{z}^{\frac{1}{\mathrm{M}}} \mathrm{W}^{\mathrm{m}}\right) \mathrm{F}_{\mathrm{k}}\left(\mathrm{z}^{\frac{1}{\mathrm{M}}} \mathrm{W}^{\mathrm{m}}\right)\right] \mathrm{X}_{\mathrm{k}}(\mathrm{z})
\end{aligned}
$$

where

$W=e^{-j 2 \pi / M}$

$\mathrm{C}(\mathrm{z})$ represents the transmission characteristics of the transmission channel. The eqn. (1) can also be expressed as in the form of transfer function as:

$$
\begin{aligned}
& \overline{\mathrm{X}}_{\mathrm{l}}(\mathrm{z}) \\
& =\sum_{\mathrm{k}=0}^{\mathrm{M}-1} \mathrm{~T}_{\mathrm{lk}}(\mathrm{z}) \mathrm{X}_{\mathrm{k}}(\mathrm{z})
\end{aligned}
$$

where $\mathrm{T}_{\mathrm{lk}}$ is the transfer function between output of $l^{\text {th }}$ subchannel and the input of $k^{\text {th }}$ sub-channel which is defined as:

$\mathrm{T}_{\mathrm{lk}}(\mathrm{z})$

$=\frac{1}{\mathrm{M}} \sum_{\mathrm{m}=0}^{\mathrm{M}-1} \mathrm{H}_{\mathrm{l}}\left(\mathrm{z}^{\frac{1}{\mathrm{M}} \mathrm{W}^{\mathrm{m}}}\right) \mathrm{C}\left(\mathrm{z}^{\frac{1}{\mathrm{M}} \mathrm{W}^{\mathrm{m}}}\right) \mathrm{F}_{\mathrm{k}}\left(\mathrm{z}^{\frac{1}{\mathrm{M}} \mathrm{W}^{\mathrm{m}}}\right)$

In case of PR-type transmultiplexer with the ideal channel, $\mathrm{T}_{\mathrm{lk}}(\mathrm{z})$ should be zero for $l \neq k$ and one for $l=k$, i.e., the total error and interference are vanished.The output at the receiver end is not a perfect replica of the input signal. These signals have distorted due to mixing of undesired interference during the processing and transmission. The amplitude of these interference signals is considered as performance measure of the designed system. The following are the performance measure parameters in the transmultiplexer system:

Inter-channel interference (ICI) and Inter-symbol interference(ISI).The ICI is the leakage of signal from the remaining (M-1) sub-channels to given particular subchannel. This occurs due to interference of the filters in their stop-band. The ICI in the $l^{\text {th }}$ sub-channel can be conveniently measured as

$$
\begin{aligned}
& E_{\text {ICI }}(\mathrm{l}) \\
& =\frac{1}{\pi} \int_{0}^{\pi}\left(\sum_{\mathrm{k}=0, \mathrm{k} \neq \mathrm{l}}^{\mathrm{M}-1}\left|\mathrm{~T}_{\mathrm{lk}}\left(\mathrm{e}^{\mathrm{j} \omega}\right)\right|^{2}\right) \mathrm{d} \omega
\end{aligned}
$$

On the other hand, ISI caused by the interference of other symbols in the same sub-channel. This occurs due to the nonideal nature of the filters within their pass-band and the fact that channel frequency response is not uniform for all subchannels. The ISI in the $l^{\text {th }}$ sub-channel can be measured as:

$$
\begin{aligned}
E_{\text {ISI }}(l)=\frac{1}{\pi} \int_{0}^{\pi}(\mid & \mathrm{T}_{\mathrm{ll}}\left(\mathrm{e}^{\mathrm{j} \omega}\right) \\
& \left.-\left.1\right|^{2}\right) \mathrm{d} \omega
\end{aligned}
$$

where $\mathrm{T}_{1 \mathrm{k}}\left(\mathrm{e}^{\mathrm{j} \omega}\right)$ and $\mathrm{T}_{11}\left(\mathrm{e}^{\mathrm{j} \omega}\right)$ can be obtained from eqn.(3).

\section{PROPOSED WORK}

\section{Prototype Filter Design}

It has been found that the whole design of Filter banks and Transmultiplexer system can be reduced to the design of a low pass prototype FIR filter and then applying cosine modulation on prototype filter, the $\mathrm{M}$-synthesis and $\mathrm{M}$ analysis filters can be configured.Up to now, several approaches have been developed for the design of filters. Of these window technique gives results equal to (or slightly better than) other methods. Also windowing approach has certain inherent advantage. In this approach, the impulse response of a Nth order causal FIR filter is obtained by multiplying the impulse response of an ideal causal low-pass filter with a window function in time domain. The window functions can be fixed, variable or combinational. But fixed window functions have certain well known limitations and have poor performance when compared to other two types of window families. Therefore in this work, the variable window functions are used to design prototype filter. The window functions under investigation are Kaiser, Cosine Hyperbolic (Cosh) and Dolph-Chebyshev (DC).The impulse response of a causal Nth order linear phase FIR filter h(n) is given as:

$\mathrm{h}(\mathrm{n})$

$=h_{d}(n) \cdot w(n)$

where $h_{d}(n)$ is the impulse response of ideal causal low-pass filter given by:

$\mathrm{h}_{\mathrm{d}}(\mathrm{n})$

$=\frac{\sin \left(\omega_{c}(n-0.5 N)\right)}{\pi(n-0.5 N)}$

where $\omega_{\mathrm{c}}$ is cut-off frequency of the ideal causal lowpass filter and $w(n)$ is the window function satisfying property $\mathrm{w}(\mathrm{N}-\mathrm{n})=\mathrm{w}(\mathrm{n})$. The order of the prototype filter using above mentioned window functions can be calculated as

$\mathrm{N}=\left\lceil\frac{\mathrm{D}}{\Delta \omega}\right\rceil+1$

where $\mathrm{D}$ is the window width parameter and $\Delta \omega$ is the normalized transition width given by 
$\Delta \omega$

$$
=\frac{\omega_{\mathrm{s}}-\omega_{\mathrm{p}}}{2 \pi}
$$

where $\omega_{\mathrm{s}}$ and $\omega_{\mathrm{p}}$ are stop-band and pass band frequencies of the ideal filter respectively. $[\mathrm{x}]$ represents the smallest integer greater than or equal to $\mathrm{x}$. A filter designed using window technique is specified by three parameters - cut-off frequency $\left(\omega_{\mathrm{c}}\right)$, filter order(N) and window width parameter (D) for the desired stop-band attenuation(A) and appropriately chosen transition width $(\Delta \omega)$.

The transmultiplexer design process starts with design of a low-pass, even order, symmetric filter with linear phase response whose amplitude response is given by

$$
\begin{aligned}
H_{0}(\omega)=\sum_{n=0}^{\frac{N}{2}-1} 2 h_{0}(n) & \cos \left(n+\frac{1}{2}\right) \omega \\
= & \sum_{n=0}^{M_{1}-1} b(n) \cos \left(n+\frac{1}{2}\right) \omega
\end{aligned}
$$

Where $M_{1}=N / 2$ and $b(n)=2 h_{0}(n)$ and eqn. (1) can be written in matrix form as:

$$
H_{0}(\omega)=b^{T} c(\omega)
$$

where $b=\left[\begin{array}{lllll}b_{0} & b_{1} & b_{2} & \ldots & b_{N / 2-1}\end{array}\right]^{T}$ and $c(\omega)=[\cos (\omega / 2)$ $\cos (3 \omega / 2) \ldots \cos (\omega(\mathrm{N}-1) / 2)]^{\mathrm{T}}$

Error in transition band can be given by eqn.(3)

$$
\begin{gathered}
\varphi_{t}=\frac{\pi}{2} \\
=\left(H_{0}(\omega)-D(\omega)\right)^{2} \text { at } \omega
\end{gathered}
$$

Error in passband can be given by eqn.(4)

$$
\begin{aligned}
\varphi_{p} & \\
& =\frac{1}{\pi} \int_{0}^{\omega_{p}}(D(\omega) \\
& \left.-H_{0}(\omega)\right)^{2} d \omega
\end{aligned}
$$

Error in stopband can be given by eqn.(5)

$$
\begin{aligned}
& \varphi_{s} \\
& =\frac{1}{\pi} \int_{\omega_{s}}^{\pi}(D(\omega) \\
& \left.-H_{0}(\omega)\right)^{2} d \omega
\end{aligned}
$$

Where

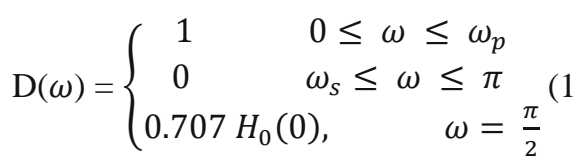

D $(\omega)$ is the amplitude response of an ideal causal low pass filter.

Using eqn.(11) and (15), the eqn.(12),(13) and (14) can be rewritten as:

$$
\begin{aligned}
& \varphi_{\mathrm{t}} \\
& =\left(\mathrm{b}^{\mathrm{T}} \mathbf{v}\right. \\
& \left.-0.707 \mathrm{H}_{0}(0)\right)^{2}
\end{aligned}
$$

where $\mathbf{v}$ is a vector equal to vector $\mathrm{c}(\omega)$, when it is evaluated at $\omega=\pi / 2$ and

$$
\begin{aligned}
& \mathrm{H}_{0}(0)=\mathrm{b}^{\mathrm{T}} \mathrm{c}(0) \\
& =\mathrm{b}^{\mathrm{T}} \mathbf{1}
\end{aligned}
$$

where $\mathbf{1}$ is a vector with all (N/2) elements equal to unity.

$\varphi_{\mathrm{p}}$

$=\mathrm{b}^{\mathrm{T}} \mathrm{Pb}$

where $\mathrm{P}$ is a real valued, symmetric matrix, given by

$\mathrm{P}$

$=\frac{1}{\pi} \int_{0}^{\omega_{\mathrm{p}}}(1$

$-c(\omega))(1-c(\omega))^{\mathrm{T}} \mathrm{d} \omega$

$\varphi_{\mathrm{s}}$

$=\mathrm{b}^{\mathrm{T}} \mathrm{Sb}$

$\mathrm{S}$ is also a real valued, symmetric matrix, which is equal to S

$=\frac{1}{\pi} \int_{\omega_{\mathrm{s}}}^{\pi} \mathrm{Cc}^{\mathrm{T}} \mathrm{d} \omega$

The objective function is formulated using weighted sum of errors in desired response given by:

$\varphi=\varphi_{\mathrm{t}}+\alpha \varphi_{\mathrm{p}}+(1-\alpha) \varphi_{\mathrm{s}}$, for $0<\alpha<1$

$\alpha$ is a constant known as performance controlling parameter which control the relative accuracies of approximation in the pass-band and stop-band

$$
\begin{array}{r}
\varphi=\left(\mathrm{b}^{\mathrm{T}} \mathrm{v}-0.707 \mathrm{H}_{0}(0)\right)^{2}+\alpha \mathrm{b}^{\mathrm{T}} \mathrm{Pb} \\
+(1-\alpha) \mathrm{b}^{\mathrm{T}} \mathrm{Sb}
\end{array}
$$

$$
\begin{array}{r}
\varphi=\left(\mathrm{b}^{\mathrm{T}} \mathrm{v}-0.707 \mathrm{H}_{0}(0)\right)^{2} \\
+\mathrm{b}^{\mathrm{T}} \mathrm{Qb}
\end{array}
$$

$\mathrm{Q}$ is the matrix given by:

Q

$$
=\alpha \mathrm{P}
$$$$
+(1-\alpha) \mathrm{S}
$$

$$
\begin{gathered}
Q(n, m)=\frac{\alpha}{\pi} \int_{0}^{\omega_{\mathrm{p}}}\left(1-\cos \left(\mathrm{n}+\frac{1}{2}\right) \omega\right) \\
\quad \times\left(1-\cos \left(\mathrm{m}+\frac{1}{2}\right) \omega\right) \mathrm{d} \omega \\
+\frac{(1-\alpha)}{\pi} \int_{\omega_{\mathrm{s}}}^{\pi}\left(\cos \left(\mathrm{n}+\frac{1}{2}\right) \omega\right) \\
\quad \times\left(\cos \left(\mathrm{m}+\frac{1}{2}\right) \omega\right) \mathrm{d} \omega
\end{gathered}
$$

Thus, the objective function is formulated in quadratic form, which can be minimized using Levenberg-Marquardt optimization algorithm. Now, the design problem of prototype filter is deduced to estimate the vector $\mathbf{b}_{i}$ such that for given value of it, the objective function is reduced to minimum value.

In this method, improved approximation of the vector $\mathbf{b}_{\mathbf{i}}$ for next iteration is given by 


$$
\begin{aligned}
& b_{i+1} \\
& =b_{i} \\
& -(H+u I)^{-1} \nabla \varphi
\end{aligned}
$$

$\mathrm{H}$ and $\nabla \varphi$ are the Hessian matrix and gradient of the objective function respectively, when it is evaluated at $b_{\mathrm{i}}$. I is the identity matrix of the order $N / 2$. The quantity $u$ is a constant called damping parameter, which is in the range of $\mathrm{u}>0$ and equal to

$\mathrm{u}$

$=\mathrm{t}(\max (\operatorname{diag}[\mathrm{H}]))$

where $\mathrm{t}$ is a constant and in range of $\mathrm{t}>0$.

The gradient $(\varphi)$ and Hessian $(\mathrm{H})$ matrix are calculated by $\nabla \varphi=2 \mathrm{Qb}+(2 \mathrm{Vb}-0.707 \mathrm{H} 0(0) \mathrm{V})$

$$
\begin{aligned}
& =2(\mathrm{Q}+\mathrm{V}) \mathrm{b} \\
& -0.707 \mathrm{H} 0(0) \mathrm{v}
\end{aligned}
$$

$$
\mathrm{H}=2(\mathrm{Q}+\mathrm{V})
$$

where $\mathrm{V}=\mathrm{vv}^{\mathrm{T}}$ and is a square matrix. Here, the damping parameter ( $u$ ) has several effects on convergence such as for all $u>0$, the coefficient matrix (Hessian matrix) is positive definite, and this ensures that $\mathrm{G}=-\mathrm{inv}(\mathrm{H}+\mathrm{uI}) \nabla \varphi$ is descent direction. For large values of $u, \mathrm{G}=-\nabla \varphi / \mathrm{u}$, that is good if the current iteration is far from the solution. Thus, the damping parameter influences both the direction and the size of the step. Using above findings, the vector $\boldsymbol{b}_{i}$ is estimated such that it results in minimum value of the objective function and it is used in obtaining the prototype filter coefficients. Thus, above findings lead an efficient method for designing the prototype filter for a cosine modulated transmultiplexer.

The desired steps required to be undertaken for designing the prototype filter using the proposed method are recorded chronologically.

1. Specify pass-band ripple $\left(r_{p}\right)$, desired stop band attenuation (As), pass-band frequency $\left(\omega_{\mathrm{p}}\right)$ and stop-band frequency $\left(\omega_{\mathrm{s}}\right)$ and sampling frequency.

2. Calculate window width (D) and window shape parameter for a given variable window function at a specific stop band attenuation using relation given in Appendix1.

3. Calculate value of cut-off frequency $\left(\omega_{c}\right)$, normalized transition width $(\Delta \omega)$ and $\operatorname{Order}(\mathrm{N})$.

4. Calculate window coefficients.

5. Obtain filter coefficients $h_{0}(n)$ by multiplying impulse response of ideal filter $\left(h_{d}(n)\right)$ with window coefficients $w(n)$

6. Assume initial values of $\alpha, \mathrm{t}$, constant (x), errors ( $\varepsilon 1$ and $\varepsilon 2)$, and counter ( $\mathrm{k}$ ).

7. Compute $\mathbf{b}_{\mathbf{i}}=2 \mathrm{~h}_{0}(\mathrm{i}), \nabla \varphi$ and $\mathbf{H}$ at $\mathbf{b}_{\mathbf{i}}$

8. Calculate $\mathbf{u}$ and the $l_{2}$ norm of gradient $\|\nabla \varphi\|$.

9. Check whether $\|\nabla \varphi\| \leq \varepsilon 1$. If yes, then compute $\mathbf{h}_{\mathbf{0}}=(1 / 2)$ $\mathbf{b}_{\mathbf{i}}$ and design cosine modulated analysis filters and synthesis filters using this value and calculate ICI and ISI. If no, follow the next step.
10. Compute $\mathbf{G}=-$ inv $(\mathbf{H}+\mathrm{uI}) \nabla \varphi$ and its $l_{2}$ norm $\|\mathbf{G}\|$ and increment the counter by 1 .

11. Check whether $\|\mathbf{G}\| \leq \varepsilon 2$. If yes, assign $\|\nabla \varphi\|=\varepsilon 1$ and go to step (9). If no, go to next Step.

12. Compute $\boldsymbol{b}_{\mathrm{i}+\mathbf{1}}$ and with this value of $\boldsymbol{b}_{\mathrm{i}+\mathbf{1}}$, calculate the value of $\mathrm{F}$

$$
=\frac{\varphi\left({ }_{b_{i}}\right)-\varphi\left({ }_{b_{i+1}}\right)}{0.5 G^{T}\left(u G-\nabla_{\varphi}\right)}
$$

13. Check whether $\mathrm{F}>0$. if no, assign $\mathrm{u}=\mathrm{ux}$ and $\mathrm{x}=2 \mathrm{x}$ and go to step (9).If yes, assign $b_{i}=b_{i+1}, x=2$ and $u=u$ max $(1 / 3,1-$ $\left.(2 \mathrm{~F}-1)^{2}\right)$

14. Compute the new values of $\nabla \varphi$ and $\mathbf{H}$ and repeat the step (9) onward.

15. Generate M-synthesis and M-analysis filters using cosine modulation of low pass prototype FIR filter $h(n)$ as:

$$
\begin{aligned}
& f_{r}(n)=2 h(n) \cos [(2 r+1) \frac{\pi}{2 M}\left(n-\frac{N}{2}\right) \\
&\left.-(-1)^{r} \frac{\pi}{4}\right] \\
& h_{r}(n)=2 h(n) \cos [(2 r+1) \frac{\pi}{2 M}\left(n-\frac{N}{2}\right) \\
&\left.+(-1)^{r} \frac{\pi}{4}\right]
\end{aligned}
$$

for $0 \leq \mathrm{r} \leq \mathrm{M}-1$ and $0 \leq \mathrm{n} \leq \mathrm{N}-1$ with $\mathrm{N}$ being the order of prototype filter. The term $(-1)^{r} \pi / 4$ is essential in order to cancel the most significant aliasing terms(related with crosstalk error in TMUX system).The most important property of the above modulation scheme is the fact that by properly designing the prototype filter transfer function, the aliased components generated in the transmitting bank due to the decimation can be totally or partially compensated in the receiving bank. Hence, this modulation technique enables one to design the prototype filter in such a way that the resulting overall bank has either PR or NPR property .The flowchart of the proposed work is shown in Appendix-II

\section{DISCUSSION OF SIMULATION RESULTS}

6. IN THE PROPOSED ALGORITHM THE INITIAL VALUES OF THE RESPECTIVE CONSTANTS (T, X,E1AND E2) FOR CARRYING OUT SIMULATION ARE $2,4,1 \times 10^{-6}, 1 \times 10^{-4}$. THIS METHOD HAS BEEN IMPLEMENTED IN MATLAB 7.1.THE COMPARISON OF PROPOSED WORK HAS BEEN DISCUSSED WITH EARLIER REPORTED WORK [7].THE PERFORMANCE OF THE METHOD HAS BEEN MEASURED IN TERMS OF FOLLOWING SIGNIFICANT PARAMETERS:

(a) Errors in transition band, pass band and stop band.

(b) Stop band attenuation As $=-20 \log _{10}\left(\mathrm{H}_{0}(\omega)\right)$ at $\omega=\omega_{\mathrm{s}}$

(c) Inter-channel interference (ICI) and Inter-symbol interference (ISI)

Example-I: A 8-channel Cosine modulated transmultiplexer designed by assuming initial filter coefficients $h=\left[h_{0}, h_{1}, h_{2} \ldots\right.$ 
$\mathrm{h}_{\mathrm{N} / 2-1}$ (filter coefficients without using any window) with following specifications: $\omega_{\mathrm{p}}=0.4 \pi, \omega_{\mathrm{s}}=0.6 \pi, \alpha=0.915$, $\mathrm{N}=24, \quad \mathrm{~h}=[0,0,0 \ldots 0.707]$; The results obtained as: $\mathrm{As}=28.31 \mathrm{~dB}, \varphi_{\mathrm{t}}=2.09 \times 10^{-8}, \varphi_{\mathrm{p}}=7.86 \times 10^{-8}, \varphi_{\mathrm{s}}=1.74 \times 10^{-5}$, $\mathrm{ICI}=-26.3 \mathrm{~dB}, \mathrm{ISI}=-13 \mathrm{~dB}$.

Example-II: A 8-channel Cosine modulated transmultiplexer designed using proposed method (filter coefficients using window function) with following specifications: $\omega_{\mathrm{p}}=0.4 \pi, \omega_{\mathrm{s}}=0.6 \pi$, Sampling frequency $=2 \pi, \alpha=0.915, \mathrm{~N}=24$.

Table 1 shows simulation results for design example II for errors in different bands of prototype filter and values of interference parameters (ICI and ISI) for 8-channel cosine modulated transmultiplexer using proposed method. When compared with the simulation results obtained in example I, a significant reduction in errors in all the band and improvent in stop-band attenuation for prototype filter and reduction in interference parameter (ICI and ISI) has been observed for same filter specification $(\mathrm{N}=24)$.

Example-III: A 8-channel Cosine modulated transmultiplexer designed using proposed method with following specification: $\omega_{\mathrm{p}}=0.1 \pi, \omega_{\mathrm{s}}=0.2 \pi, \alpha=0.95$, As $=50 \mathrm{~dB}$

Table-2 shows comparison of performance parameter obtained for protoype filter and 8-channel cosine modulated transmultiplexer designed using different window function for fixed stop-band attenuation $\mathrm{As}=50 \mathrm{~dB}$. The Cosh window gives better performance when compared to Kaiser and DC window in terms of interference parameters and errors in all three bands but for slightly higher order. Figure 2 shows simulation result. Since transmultiplexer multiplexes the multiple data coming from different sources, therefore it is necessary to analyze the ICI level in each sub-channel which is shown in Table 3 .

Example IV: A 8-channel CMT is designed at As $=100 \mathrm{~dB}$ and $\mathrm{N}=64$ using proposed method and is compared with earlier reported work by Soni.et.al [6] for Kaiser window. The simulation result is shown in fig. 3

Table 1 shows the comparative study of different window function used for designing prototype filter and 8-channel CMT at fixed stop band attenuation and pass band and stop band frequencies. The Cosh window shows improved results as compared to Kaiser and DCwindow in terms of ICI and ISI for a particular sub channel. Comparison of the proposed method is done with earlier reported work in [6] using Kaiser window in Table 2 which shows improvement in interference level for same order and stop-band attenuation.

Table 1: Prototype filter and 8-channel CMT performance parameter using proposed method for stop-band attenuation $\mathrm{As}=\mathbf{5 0 \mathrm { dB }}$

\begin{tabular}{|c|l|l|l|l|l|c|}
\hline $\begin{array}{l}\text { Windo } \\
\mathbf{w}\end{array}$ & $\mathbf{N}$ & $\emptyset_{\boldsymbol{t}}$ & $\emptyset_{\boldsymbol{p}}$ & $\emptyset_{\boldsymbol{s}}$ & $\begin{array}{c}\text { ICI } \\
(\mathbf{D B})\end{array}$ & $\begin{array}{c}\text { ISI } \\
(\mathbf{D B})\end{array}$ \\
\hline Kaiser & 6 & 7.7 & 3.6 & 1.8 & - & -63.53 \\
& 0 & $\begin{array}{l}1 \times \\
10^{-7}\end{array}$ & $\begin{array}{l}2 \times \\
10^{-11}\end{array}$ & $\begin{array}{l}8 \times \\
10^{-6}\end{array}$ & 126.30 & \\
\hline Cosh & 6 & 3.1 & 2.2 & 6.1 & - & -82.92 \\
& 4 & $\begin{array}{l}5 \times \\
2 \times\end{array}$ & $\begin{array}{l}5 \times \\
10^{-1}\end{array}$ & 164.97 & \\
& & $10^{-8}$ & & \\
\hline DC & 6 & 4.2 & 1.7 & 4.0 & - & -72.64 \\
\hline
\end{tabular}

\begin{tabular}{|l|l|l|l|l|l|l|}
\hline & 4 & $\begin{array}{l}1 \times \\
10^{-8}\end{array}$ & $\begin{array}{l}8 \times \\
10^{-11}\end{array}$ & $\begin{array}{l}5 \times \\
10^{-7}\end{array}$ & 143.43 & \\
& & & \\
\hline
\end{tabular}

Finally, Table 3 shows comparison of proposed work with earlier reported work by Kumar.et.al [7]. The simulation result clearly shows the reduction in errors in different regions of prototype filter and peak reconstruction error when usingwindowing technique for generating initial filter coefficient than without using any window function.

Table 2: Performance comparison of proposed method for 8-Channel cosine modulated Tmux at stop-band attenuation $\mathrm{As}=100 \mathrm{~dB}$ and order $\mathrm{N}=64$

\begin{tabular}{|c|c|c|c|c|c|}
\hline $\begin{array}{c}\text { Type of } \\
\text { method }\end{array}$ & $\begin{array}{c}\text { Window } \\
\text { function }\end{array}$ & $\mathbf{N}$ & $\boldsymbol{\omega}_{\boldsymbol{c}}$ & $\begin{array}{c}\text { ICI } \\
(\mathbf{D B})\end{array}$ & $\begin{array}{c}\text { ISI } \\
(\mathbf{D B})\end{array}$ \\
\hline $\begin{array}{c}\text { Reported } \\
\text { work[6] }\end{array}$ & Kaiser & 64 & $0.11 \pi$ & -92.43 & -72.22 \\
\hline $\begin{array}{c}\text { Proposed } \\
\text { work }\end{array}$ & Kaiser & 64 & $0.5 \pi$ & -94.45 & -74.38 \\
\hline
\end{tabular}

Table 3: Relative performance of proposed method for $\mathrm{N}=\mathbf{2 4}$

\begin{tabular}{|c|c|c|c|c|c|}
\hline $\begin{array}{l}\text { Type of } \\
\text { method }\end{array}$ & $A s(d B)$ & $\emptyset_{t}$ & $\emptyset_{p}$ & $\emptyset_{s}$ & $\begin{array}{l}\text { PRE } \\
(d B)\end{array}$ \\
\hline $\begin{array}{l}\text { Kumar. } \\
\text { et.al[7] }\end{array}$ & 28.31 & $\begin{array}{c}2.09 \times \\
10^{-8}\end{array}$ & $\begin{array}{l}7.86 \times \\
10^{-8}\end{array}$ & $\begin{array}{l}1.75 x \\
10^{-5}\end{array}$ & 0.0171 \\
\hline \multicolumn{6}{|c|}{ Proposed } \\
\hline Kaiser & 42 & $\begin{array}{l}3.36 \times \\
10^{-10}\end{array}$ & $\begin{array}{l}2.28 \times \\
10^{-11}\end{array}$ & $\begin{array}{c}9.9 \times \\
10^{-10}\end{array}$ & 0.0142 \\
\hline Cosh & 39 & $\begin{array}{l}3.42 \times \\
10^{-10} \\
\end{array}$ & $\begin{array}{l}2.31 \times \\
10^{-11} \\
\end{array}$ & $\begin{array}{l}1.03 \times \\
10^{-10} \\
\end{array}$ & 0.0151 \\
\hline $\mathrm{DC}$ & 58 & $\begin{array}{l}3.95 \times \\
10^{-10}\end{array}$ & $\begin{array}{l}3.00 \times \\
10^{-11} \\
\end{array}$ & $\begin{array}{c}9.69 \times \\
10^{-10} \\
\end{array}$ & 0.0154 \\
\hline
\end{tabular}

Table-4 Comparison of ICI(dB) for different subchannels for $\mathrm{As}=50 \mathrm{~dB}$

\begin{tabular}{|l||l||l|l||}
\hline $\begin{array}{l}\text { Sub- } \\
\text { channel }\end{array}$ & Kaiser(N=60) & $\operatorname{Cosh}(\mathbf{N}=64)$ & DC(N=64) \\
\hline \hline 0 & -126.30 & -164.97 & -143.43 \\
\hline \hline 1 & -126.45 & -163.89 & -142.65 \\
\hline \hline 2 & -126.36 & -163.47 & -143.78 \\
\hline \hline 3 & -125.85 & -164.39 & -143.47 \\
\hline \hline 4 & -126.26 & -163.27 & -143.05 \\
\hline \hline 5 & -126.36 & -163.47 & -142.45 \\
\hline \hline 6 & -126.45 & -163.89 & -143.43 \\
\hline \hline 7 & -121.70 & -161.36 & -139.28 \\
\hline
\end{tabular}




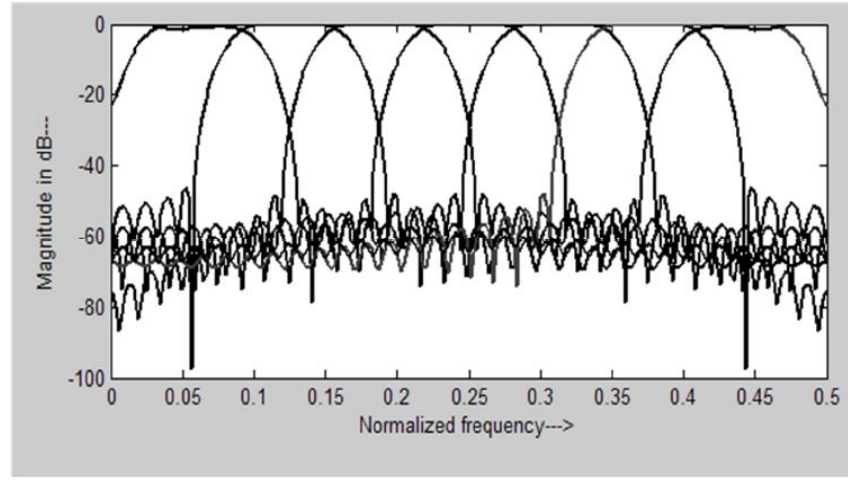

(a)

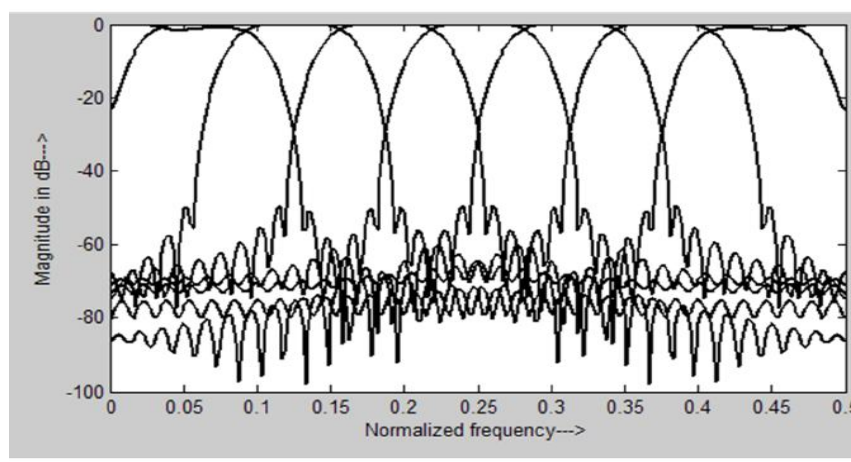

(b)

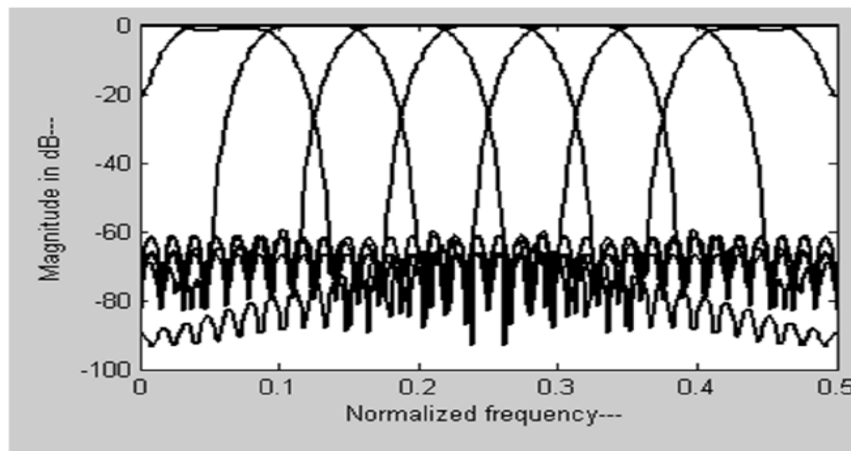

(c)

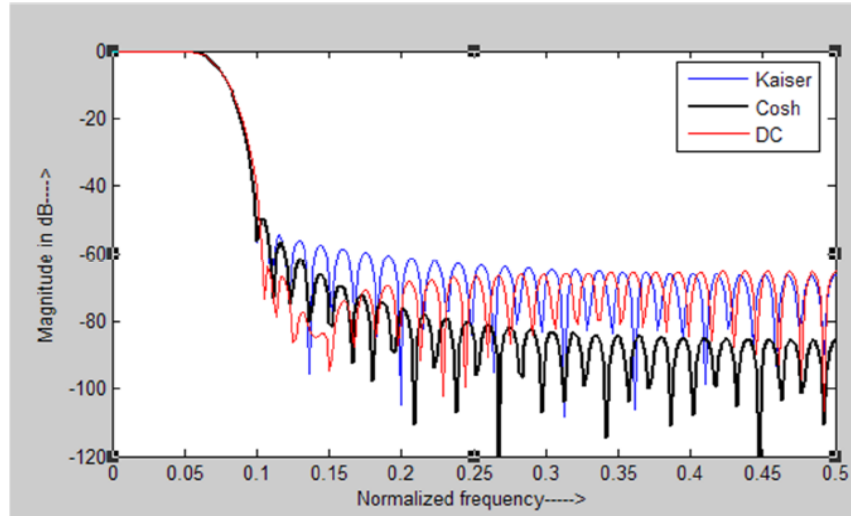

(d)

Figure 2: 8-channel cosine modulated Tmux using (a) Kaiser Window (b) Cosh window (c) DC window(d) Magnitude response for prototype filter at stop-band attenuation $\mathrm{As}=\mathbf{5 0 \mathrm { dB }}$.

Figure 2 shows simulation result. Since Trans-multiplexer multiplexes the multiple data coming from different sources, therefore it is necessary to analyze the ICI level in each subchannel. Table-4 shows the comparison.

\section{CONCLUSION}

In this paper, an improved and efficient approach for designing an optimized near perfect reconstruction type trans-multiplexer has been proposed. The performance parameters has been Inter channel interference and Inter symbol interference which depends on the design of filters used in analysis and synthesis sections of trans-multiplexer system. These filters are synthesized using cosine modulation of a single low-pass prototype filter, which is computationally efficient technique than general method of designing each sub-filter individually. It has been noticed that the design of low-pass prototype filter is a crucial factor. The filter has been designed using windowing technique since it is simple and convenient and provides same or better performance than any other technique of filter design. Variable window has been used for this purpose since they provide high stop-band attenuation and side lobe fall-off rate over fixed window function. Then a nonlinear and iterative optimization technique was applied to reduce errors in pass band, transition band and stop-band of prototype filter by varyingfilter coefficients at each iteration.

The simulation results reveal that window baseddesign of optimized filter have smaller value of errors in different regions of filter reconstruction error for two channel QMF bank and interference parameters in transmultiplexer system when compared to non-window based design. Also the amountof interference level in different sub-channels is found to be same for fixed value of stop-band attenuation for different window function used. So there is no burden of selecting aparticular sub-channel for a given application. The different design examples concludethat the proposed design of trans-multiplexer is suitable for different attenuation and filterlength and can be used in wide range of application.

\section{REFERENCE}

[1] R.K.Soni, A.Jain, R.Saxena, "An improved and simplified design of pseudo trans-multiplexer using Blackman window family," Digital Signal Processing Vol.20, no.3, pp.743-749, 2010.

[2] D.Lacroix, N. Goudard, M.Alard, "OFDM with guard interval versus OFDM/Offset QAM for high data rate UMTS downlink transmission," Proceedings of IEEE Conference on Vehicular Technology, pp. 2682-2686, 2001.

[3] G.Cherubini, E.Eleftheriou, S.Olcer, "Filtered Multitone modulation for very high-speed digital subscriber lines". IEEE J. Sel. Areas Commun. Vol.20, pp.1016-1028, 2002.

[4] A.K.Akansu and X.Lin, "A comparative performance evaluation of DMT (OFDM) and DWMT (DSBMT) based DSL communications systems for single and multitone interference," in Proceedings of the 1998 IEEE International Conference on Acoustics speech and Signal Processing, vol.6, pp. 3269-3273,1998.

[5] C.W. Kok, W. C. Siu, and Y. M. Law, "Peak constrained least-squares QMF banks," Signal Processing, Vol. 88, No. 10, pp. 2363-2371, 2008. 
[6] R.K.Soni, A.Jain, R.Saxena, "An optimized transmultiplexer using combinational window functions," Signal, Image and Video Processing, Online, April 2010.

[7] A. Kumar, G.K.Singh, R.S. Anand, "An improved method for designing quadrature mirror filter banks using the Levenberg-Marquardt optimization," Signal, Image and Video processing, published online, 2011.

\section{APPENDIX-I}

\section{Window functions and their filter design relationships}

1. Kaiser window: The window function is given by

$\mathrm{w}(\mathrm{n})=\frac{\mathrm{I}_{0}\left(\beta \sqrt{1-\left(1-\frac{2 \mathrm{n}}{\mathrm{N}-1}\right)^{2}}\right)}{\mathrm{I}_{0}(\beta)}, 0 \leq \mathrm{n} \leq \mathrm{N}-1$

where $I_{0}[$.$] is the zeroth order modified Bessel function of$ the first kind.

$\beta$ is the window shape parameter and $\mathrm{N}$ is the length of the window.

$\mathrm{I}_{0}(\mathrm{x})=1+\left(0.25 \mathrm{x}^{2}\right) / \operatorname{fact}(1)+\left(\left(0.25 \mathrm{x}^{2}\right)\right)^{2} / \operatorname{fact}(3)+((0.25$ $\left.\left.\mathrm{x}^{2}\right)\right)^{3} / \operatorname{fact}(5)+$

The empirical design equations are given by

$\beta$

$=\left\{\begin{array}{lr}0, & \mathrm{~A} \leq 21 \\ 0.5842(\mathrm{~A}-21)^{0.4}+0.07886(\mathrm{~A}-21), & 21<A \leq 50 \\ 0.1102(A-8.7), & A>50\end{array}\right.$

$$
D= \begin{cases}0.9222, & A \leq 21 \\ \frac{A-7.95}{14.36}, & A>21\end{cases}
$$

2. Cosh Window: The window function is given by

$$
\mathrm{w}(\mathrm{n})=\frac{\operatorname{Cosh}\left(\gamma \sqrt{1-\left(1-\frac{2 \mathrm{n}}{\mathrm{N}-1}\right)^{2}}\right)}{\operatorname{Cosh}(\gamma)}, \quad 0 \leq \mathrm{n}
$$

where, $\operatorname{Cosh}(\mathrm{x})$ is the hyperbolic cosine function of $\mathrm{x}$ expressed as:

$\operatorname{Cosh}(x)=\frac{e^{x}+e^{-x}}{2}$

$\gamma$ is the window shape parameter and $\mathrm{N}$ is the length of the window.
The empirical design equations are given by

$\gamma$

$$
=\left\{\begin{array}{cc}
0, & \mathrm{~A}<20.8 \\
0.2445(\mathrm{~A}-20.8)^{0.4}+0.1169(\mathrm{~A}-20.8), & 20.8 \leq \mathrm{A}<50 \\
-8.722 \times 10^{-5} A^{2}+0.1335 A-1.929, & 50 \leq A \leq 120
\end{array}\right.
$$

$\mathrm{D}$

$$
=\left\{\begin{array}{cc}
0, & \mathrm{~A}<20.8 \\
3.03 \times 10^{-4} \mathrm{~A}^{2}+0.05246 \mathrm{~A}-0.2397, & 20.8 \leq \mathrm{A}<50 \\
-7.771 \times 10^{-6} A^{2}+0.07432 A-0.5402, & 50 \leq A \leq 120
\end{array}\right.
$$

3. Dolph-ChebyshevWindow(DC): The window function is given by

$$
\begin{aligned}
& \mathrm{w}(\mathrm{n}) \\
& = \begin{cases}\frac{1}{\mathrm{~N}+1}\left(\frac{1}{\mathrm{r}}+2 \sum_{\mathrm{i}=1}^{\mathrm{N} / 2} \mathrm{C}_{\mathrm{N}}\left[\mathrm{x}_{0} \cos \left(\frac{\mathrm{i} \pi}{\mathrm{N}+1}\right) \cos \left(\frac{2 \mathrm{ni} \pi}{\mathrm{N}+1}\right)\right]\right), & |\mathrm{n}| \leq \frac{\mathrm{N}}{2} \\
0 & |\mathrm{n}|>\frac{\mathrm{N}}{2}\end{cases}
\end{aligned}
$$$$
r=\frac{A_{s}}{A_{p}}
$$

$A_{p}$ is the desired pass-band ripple and $A_{s}$ is the desired stop-band attenuation

$$
\begin{gathered}
\mathrm{x}_{0}=\cosh \left[\frac{1}{\mathrm{~N}} \cosh ^{-1}\left(\frac{1}{\mathrm{r}}\right)\right] \\
\mathrm{C}_{\mathrm{N}}(\mathrm{x})= \begin{cases}\cos \left(\mathrm{N} \cos ^{-1}(\mathrm{x})\right), & |\mathrm{x}| \leq 1 \\
\cosh \left(\mathrm{N} \cosh ^{-1}(\mathrm{x})\right), & |\mathrm{x}|>1\end{cases} \\
\mathrm{D}= \begin{cases}0.9222, & |\mathrm{~A}| \leq 21 \\
\frac{\mathrm{A}-5.45}{14.36}, & |\mathrm{~A}|>21\end{cases}
\end{gathered}
$$

where $\mathrm{D}$ is the window width and $\mathrm{A}$ is the minimum Stop-band attenuation in $\mathrm{dB}$ 


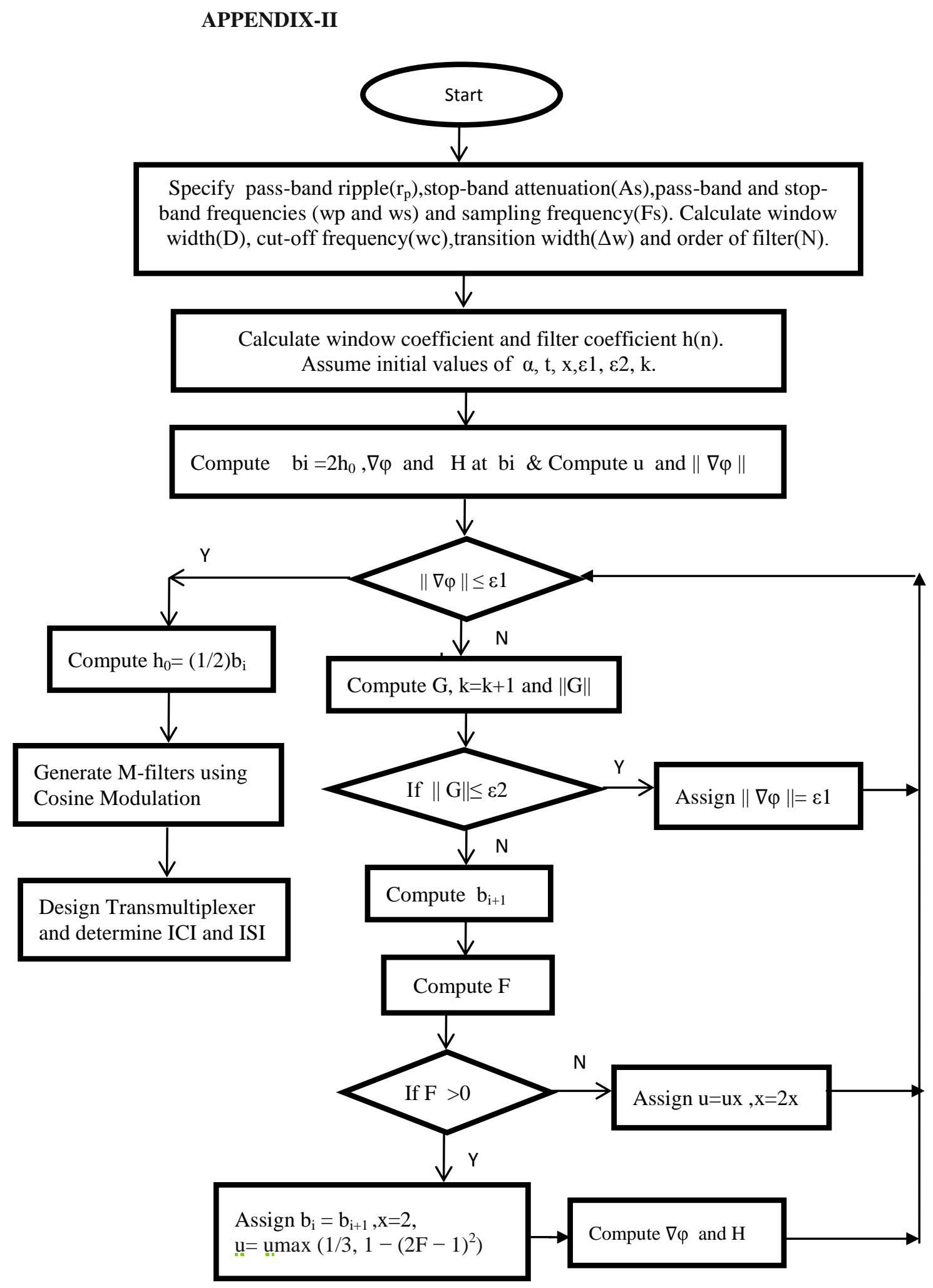

Figure 4:

Flowchart of the

Proposed work 